\title{
HYDROGEN DEFLAGRATION SIMULATIONS UNDER TYPICAL CONTAINMENT CONDITIONS FOR NUCLEAR SAFETY
}

\author{
J. Yáñez, A. Kotchourko, A. Lelyakin \\ Institute for Energy and Nuclear Technology, Karlsruhe Institute of Technology, \\ Kaiserstraße 12, 76131 Karlsruhe, Germany
}

\begin{abstract}
This paper presents the modeling of low-concentration hydrogen deflagrations performed with the recently developed KYLCOM model. Three experiments carried out in THAI facility (performed in the frames of international OECD THAI experimental program) were selected for the simulation exercise. The tests allow studying lean mixture hydrogen combustion at normal ambient, elevated temperature and superheated and saturated conditions. The experimental conditions considered together with the facility size and shape grant a high relevance degree to the typical NPP containment conditions. The results of the simulations were thoroughly compared with the experimental data, and the comparison was supplemented by the analysis of the combustion regimes taking place in the considered tests. Results of the analysis demonstrated that despite the comparatively small difference in mixture properties, three different combustion regimes can be definitely identified.
\end{abstract}

\section{INTRODUCTION}

The THAI experimental containment research program has been extensively used in code validation activities (Clement, 2007). On the basis of the delivered data, the physical models for the description of complicated distribution and combustion phenomena applicable in accidental conditions in nuclear power plants (NPP), were improved and developed. Several areas of interest for nuclear reactor containment applications were studied. Extensive test program concerning thermal hydraulics, hydrogen distribution and combustion, aerosol and iodine (fission products) behavior have been conducted.

As a part the licensing process of the reactor containment, the threat of uncontrolled hydrogen release and combustion must be addressed. The state-of-the-art mitigation systems can reduce significantly the risk of such an accident. Nevertheless, under severe circumstances, scenarios consisting of low $\mathrm{H}_{2}$ concentration deflagration processes must be assessed.

The general objective of the study reported in the current paper is to address hydrogen deflagrations in lean mixtures with vertical flame propagation. The selected conditions can be considered as close to those typical under accidental situation in NPP; among them, the size and shape of the facility, the elevated initial temperature, pressure, and steam concentrations.

\section{EXPERIMENTS}

The main component of the THAI facility is the cylindrical steel vessel of $9.2 \mathrm{~m}$ height and $3.2 \mathrm{~m}$ diameter, with a total volume of $60 \mathrm{~m}^{3}$ depicted in Figure 1. At the lower end of the container a sump compartment is attached. Cooling/heating jackets, subdivided in three vertical sections, were set up in the outer cylindrical wall. The entire vessel was thermally insulated with a double-wall, being the inner wall $22 \mathrm{~mm}$ thick and the outer wall made from 6-mm stainless steel. The $16.5-\mathrm{mm}$ gap between the walls is filled with thermal oil. The outside wall is insulated by the 120-mm Rockwool layer.

Fifteen continuously operating lines took gas samples from the vessel atmosphere at different locations (see Figure 1 left) prior and after hydrogen combustion. An axial fan, located near the 
hydrogen distributor, homogenized the vessel atmosphere prior to ignition. The accuracy of concentrations measurements was reported to be smaller than $0.02 \%$ vol. The temperature of the gases prior to ignition was measured by five calibrated thermocouples. Additionally, 43 fast sheathed thermocouples were installed at 13 different elevations in the test vessel to monitor flame propagation and flame temperature during the combustion (Figure 1 right). The transient deflagration pressure was monitored by four fast pressure transducers (strain gauge type). The fitting of the whole implementation from inside could be observed in Figure 2.
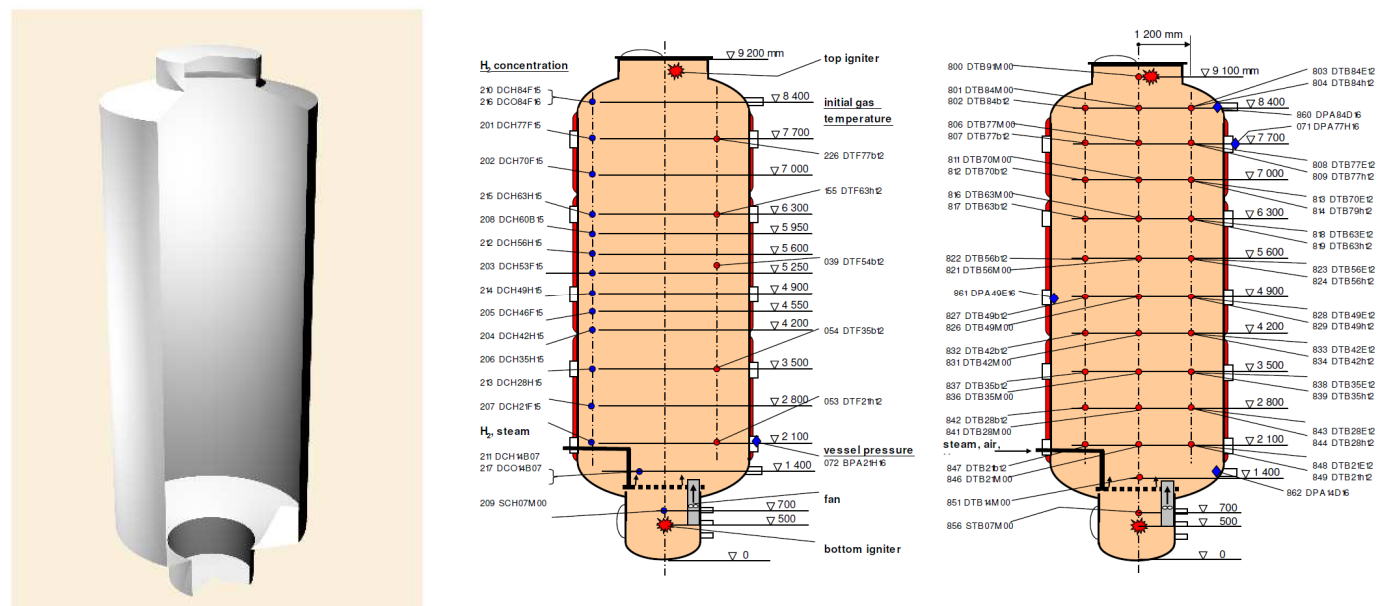

Figure 1: Left: General external view of the THAI facility. Center and right: instrumentation positions. Center: concentration measurement. Right: fast thermocouples location.

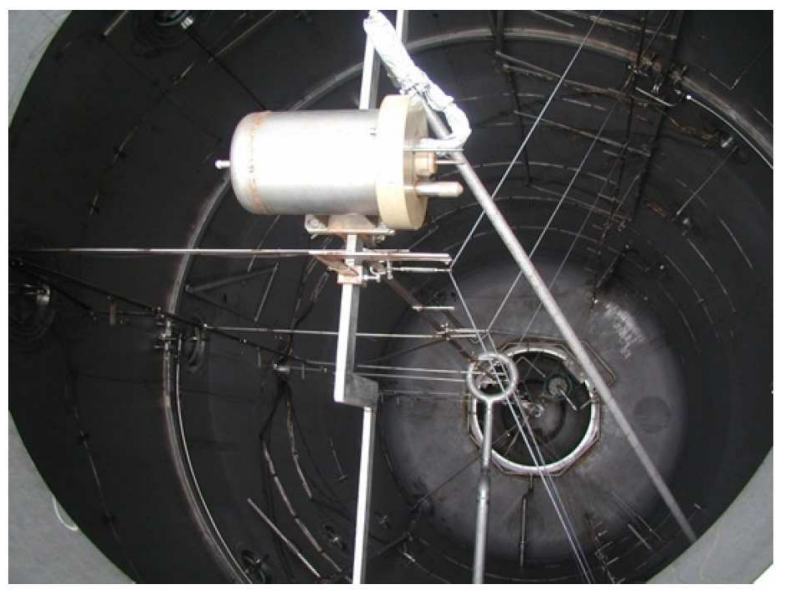

Figure 2: Internal view of the vessel. Igniter (down in sump) and instrumentation fittings (triangular setup).

Inside the OECD-NEA 'International Standard Problem ISP-49' program, three tests, from the total matrix of THAI experimental program containing 29 hydrogen deflagration experiments, were selected for benchmarking. The simulation exercise was divided in two phases. An 'open' phase, including test HD-12 and its repetition HD-2R, was performed knowing the results of the experiments to improve the modeling capabilities. This was followed by a 'blind' phase in which predictive precalculations as well as corrective post-calculations were carried out.

The experiments chosen deal with uniform mixtures and upwards flame propagations. In all cases, the ignition position was centered in the sump compartment (Figure 1 center and right, sump area marked in red). Additionally to the ISP-49 program the authors performed simulation of the test HD- 15 . The 
experimental details of the test HD 15 are omitted from the body of article due to non-disclosure agreement acting on the data from the mentioned above OECD THAI experimental program. Both experiments HD-12 and HD-15 allow studying low-concentration combustion of hydrogen at ambient and elevated temperature respectively. With the aim to test the capability of the utilized combustion models to produce adequate results in hydrogen-air-steam atmospheres, an experiment HD-22 was chosen to simulate the deflagration of a $\mathrm{H}_{2}$-steam-air mixture at superheated and saturated conditions. The conditions of the experiments selected were summarized in the Table 1. Further details could be obtained from references (Kanzleiter, 2007, 2007b, 2007c). As a result of the experiments detailed recordings of flame propagation, pressure transients, temperature transients and combustion completeness was obtained.

Table 1: Summarized conditions for the THAI Hydrogen Deflagration Tests.

\begin{tabular}{ccccccc}
\hline Name & $\begin{array}{c}\text { Pressure, } \\
\text { bar }\end{array}$ & $\begin{array}{c}\text { Temp., } \\
\mathbf{C}^{\circ}\end{array}$ & $\begin{array}{c}\text { Conc. of } \mathbf{H}_{2} \\
\text { vol.\% }\end{array}$ & $\begin{array}{c}\text { Conc. of Steam, } \\
\text { vol. \% }\end{array}$ & $\begin{array}{c}\text { Max. pressure, } \\
\text { bar }\end{array}$ & $\begin{array}{c}\text { Max. } \\
\text { temp., K }\end{array}$ \\
\hline HD-12 & 1.492 & 18 & 8.1 & 0 & 5.05 & 765 \\
\hline HD-15 & 1.504 & 93 & 9.9 & 0 & - & - \\
\hline HD-22 & 1.487 & 92 & 9.9 & 25 & - & - \\
\hline
\end{tabular}

\section{NUMERICAL SIMULATIONS}

The calculations were performed with the 'in house' COM3D code (Kotchourko, 1999). COM3D is a fully explicit finite differences parallelized combustion code developed in Karlsruhe Institute of Technology. The main characteristics of the code employed to carry out the simulations of the current work are summarized in the Table 2.

Table 2: COM3D characteristics. Types of discretization schemes, time steps requirements and computational resources used.

\begin{tabular}{cccc}
\hline $\begin{array}{c}\text { Type of solver and } \\
\text { pressure-velocity } \\
\text { coupling }\end{array}$ & $\begin{array}{c}\text { Discretization } \\
\text { scheme }\end{array}$ & $\begin{array}{c}\text { Time step } \\
\text { requirements }\end{array}$ & $\begin{array}{c}\text { CPU type, RAM used and CPU } \\
\text { time }\end{array}$ \\
\hline $\begin{array}{c}\text { Finite differences Fully } \\
\text { compressible scheme }\end{array}$ & $\begin{array}{c}\mathrm{C}^{1}=\text { Ami Harten, } \\
\mathrm{TVD} 2^{\text {nd }} \text { order non- } \\
\text { oscilative, }\end{array}$ & $\begin{array}{c}\mathrm{CFL}=0.94, \\
\mathrm{D}=0.45\end{array}$ & $\begin{array}{c}32 \text { processors Opteron-AMD } \\
\text { CPU type, } 1 \text { GB RAM per } \\
\text { processor. CPU time: } \sim 5 \text { days }\end{array}$ \\
& $\begin{array}{c}\mathrm{D}=2^{\text {nd }} \text { order } \\
\text { central differences, }\end{array}$ \\
& $\begin{array}{c}\mathrm{T}=2^{\text {nd }} \text { order } \\
\text { explicit }\end{array}$ \\
& & \\
\hline
\end{tabular}

For the selection of the turbulence modeling the recommendations contained in the reference (Mahaffy, 2007) were taken into account. The simulations were performed with the standard k- $\varepsilon$ turbulence model (Launder, 1974). The resolution adopted prevented the use of Large Eddy Simulation (LES) modeling (for details about resolution requirements see (Jimenez, 2004)). The initial level of turbulence and dissipation was selected making the turbulent viscosity of the same order of magnitude of the molecular one (Arntzen, 1998). To do so, values of $\mathrm{k}$ and $\varepsilon$ equal to $10^{-4}\left(\mathrm{~m}^{2} / \mathrm{s}^{2}\right.$ and $\mathrm{m}^{2} / \mathrm{s}^{3}$ respectively) were adopted.

The combustion model chosen was the KYLCOM model (Yanez, 2010). This methodology belongs to the 'flame speed'-based category, and has two relatively independent parts. The first one is responsible for the correct evaluation of the turbulent flame speed in the current local conditions, while the second

\footnotetext{
${ }^{1} \mathrm{C}$, Convection terms, D, diffusion terms, T, temporal terms.
} 
one provides the flame propagation in the simulated media with the evaluated speed. Based on the results from the reference (Yanez, 2010), the correlation for the evaluation of turbulent burning velocity proposed by Schmidt (1998) was utilized for the modeling

$\mathrm{S}_{\mathrm{t}}=\mathrm{S}_{\mathrm{L}}+\frac{\mathrm{u}^{\prime}}{\sqrt{1+\frac{1}{\mathrm{Da}^{2}}}}$,

where $S_{t}$ is estimated turbulent flame speed, $S_{L}$ is the laminar flame speed and Da is the Damköhler number.

It was found that in one of the experiments the used method did not provide fully suitable results. Further examination of the experimental observations disclosed the fact that the test under consideration was differed from the others by considerable sound effect. This can be seen at the pressure history in Figure 4. Additional physical mechanisms responsible for this effect appears to be important for correct accounting of such events; therefore further model development was performed with the view to simulate the mass consumption rate enhancement due to parametric instability; see e.g. (Bychkov, 2000). The same procedure utilized by Bauwens (2008) aimed to take into account the effects of the Rayleigh-Taylor instability was followed. In this method, the surface wrinkling factor $\Xi$ characterizes flame surface enhancement due to the instability. It is determined from a differential equation which describes the surface dynamics taking into account the competition between its growth and its shrinking

$\frac{d \Xi}{d t}=G(\Xi-1)-R(\Xi-1)^{\frac{3}{2}}$.

The sub-grid wrinkling removal rate, $\mathrm{R}$, represents the flame propagation and annihilation of the flame surface at cusps and is given by the formula

$R=\frac{8 \sigma S_{L} k}{\pi}$,

where $\mathrm{k}$ represent the wavenumber with the highest amplification. The sub-grid wrinkling generation rate, G, may be calculated from its expression in the literature (Bychkov, 1999)

$\left(A G^{2}-\frac{1}{4} A \omega^{2}+B S_{L} k G-C S_{L}^{2} k^{2}+C_{l} g k\right)^{2}+\omega^{2}\left(A G+\frac{1}{2} B S_{L} k\right)^{2}-\frac{1}{4} \omega^{2} C_{l}^{2} U_{a}^{2} k^{2}=0$,

where $\mathrm{A}, \mathrm{B}, \mathrm{C}, \mathrm{C}_{1}$, are dimensionless coefficients depending on the flame parameters and the wavenumber, see formulas (3.66)-(3.69) in (Bychkov, 2000), $\mathrm{U}_{\mathrm{a}}$ and $\omega$ are the amplitude and the circular frequency of the acoustic perturbations. Some limitations exists for the evaluation of R and G. A linear model was applied in the deduction of the theoretical expressions. Therefore, the formulas are only applicable for small amplitude disturbances. Additionally, the values for $R$ and $G$ were considered to be constant during the whole calculations. The wavenumber $\mathrm{k}$ was also considered as a constant in this formulation. For all those reasons, the values of $\mathrm{G}$ and $\mathrm{R}$ must be considered only as estimative.

Once the burning velocity is available, the corresponding flame advancing is provided by the 'forest fire' CREBCOM algorithm (Efimenko, 2001). This method is based on the solution of a transport equation for the progress variable $\mathrm{f}$, a normalized burned out mixture fraction,

$\frac{\partial \rho f}{\partial t}+\frac{\partial \rho u_{i} f}{\partial x_{i}}=\frac{\partial}{\partial x_{i}}\left(\rho D_{t} \frac{\partial f}{\partial x_{i}}\right)+\Phi$,

where, $\rho$ is density, $u_{i}$ is the $i$-th component of the flow speed and $D_{t}$ is the turbulent diffusion coefficient. The normalized chemical reaction rate $\Phi$ is described by the equation

$\Phi=\left\{\begin{array}{cc}\frac{\rho C_{g}}{\Delta}\left(1-f_{i, j, k}\right) & F_{i, j, k}>\left(\frac{1}{2}\right)^{2} \\ 0 & F_{i, j, k}<\left(\frac{1}{2}\right)^{2},\end{array}\right.$

where $\mathrm{F}_{\mathrm{i}, \mathrm{j}, \mathrm{k}}$, is the 'control parameter', $\mathrm{C}_{\mathrm{g}}$ is the 'model parameter' and $\Delta$ the computation cell size. If the value of $\mathrm{F}_{\mathrm{ijk}}$ for the cell $(\mathrm{i}, \mathrm{j}, \mathrm{k})$, calculated with the expression 
$\mathrm{F}_{\mathrm{i}, \mathrm{j}, \mathrm{k}}=\mathrm{f}_{\mathrm{i}+1, \mathrm{j}, \mathrm{k}}^{2}+\mathrm{f}_{\mathrm{i}-1, \mathrm{j}, \mathrm{k}}^{2}+\mathrm{f}_{\mathrm{i}, \mathrm{j}+1, \mathrm{k}}^{2}+\mathrm{f}_{\mathrm{i}, \mathrm{j}-1, \mathrm{k}}^{2}+\mathrm{f}_{\mathrm{i}, \mathrm{j}, \mathrm{k}+1}^{2}+\mathrm{f}_{\mathrm{i}, \mathrm{j}, \mathrm{k}-1}^{2}-3 \mathrm{f}_{\mathrm{i}, \mathrm{j}, \mathrm{k}}^{2}$,

exceeds the critical quantity of 0.25 a cell is considered to be burning, otherwise it remains un-ignited. The 'model parameter' $\mathrm{C}_{\mathrm{g}}$ links the flame propagation model with the estimated flame propagation speed and expansion ratio via the formula,

$\mathrm{C}_{\mathrm{g}}=(\mathrm{A} \cdot \sigma+\mathrm{B}) \mathrm{S}$,

in which, $\sigma$ is the expansion ratio, $\mathrm{S}$ the flame velocity and $\mathrm{A}, \mathrm{B}$, are correlation constants obtained from numerical experiments with the values equal to 0.243 for constant $\mathrm{A}$ and 0.375 for constant $\mathrm{B}$.

In the selection of the grid resolution, which is one of the important parameters for CFD, the coupling criteria between mesh resolution and the recommendations presented in (Mahaffy, 2007) for the turbulence modeling was taken into account. The use of relatively coarse mesh $(5 \mathrm{~cm}$ cell size) were dictated by the time constrains of the current simulations. The summary of the mesh used to perform the calculations is contained in Table 3 .

Table 3: Characteristics of the numerical mesh used in the calculations

Type of grid

Orthogonal structured equidistant
Domain size, cells

$63 \times 184 \times 63$
Cell size, $\mathbf{m}$

0.05

Number of cells

730296

\section{RESULTS AND ANALYSIS}

\subsection{Results of the simulations. Pressure, temperature, flame possition and velocity}

The Figure 3 and Figure 4 show the comparison between experiments and calculations for the pressure, flame position and velocity in the experiments HD-12 and HD-22 respectively. The Figure 5 shows the temperature iso-surface for the HD-12 problem. The streamlines seeing in the picture give an idea about the general stream pattern created in the enclosure by the buoyancy of the hot combustion products. The flow pattern represented for the HD-22 is very similar (Figure 6). The difference can be easily seen in the lower part of the facility, where in the second case a distinct flame stem appears connecting the sump area and the plume of the combustion products. The occurring of this stem, which is also present in the HD-22 calculation, is due to the existence of a circulation flow pattern created by the buoyant flame. This rotating motion in the tests HD-15 and HD-22 is more intensive than in case HD12 and results therefore in the creation of this new structure.
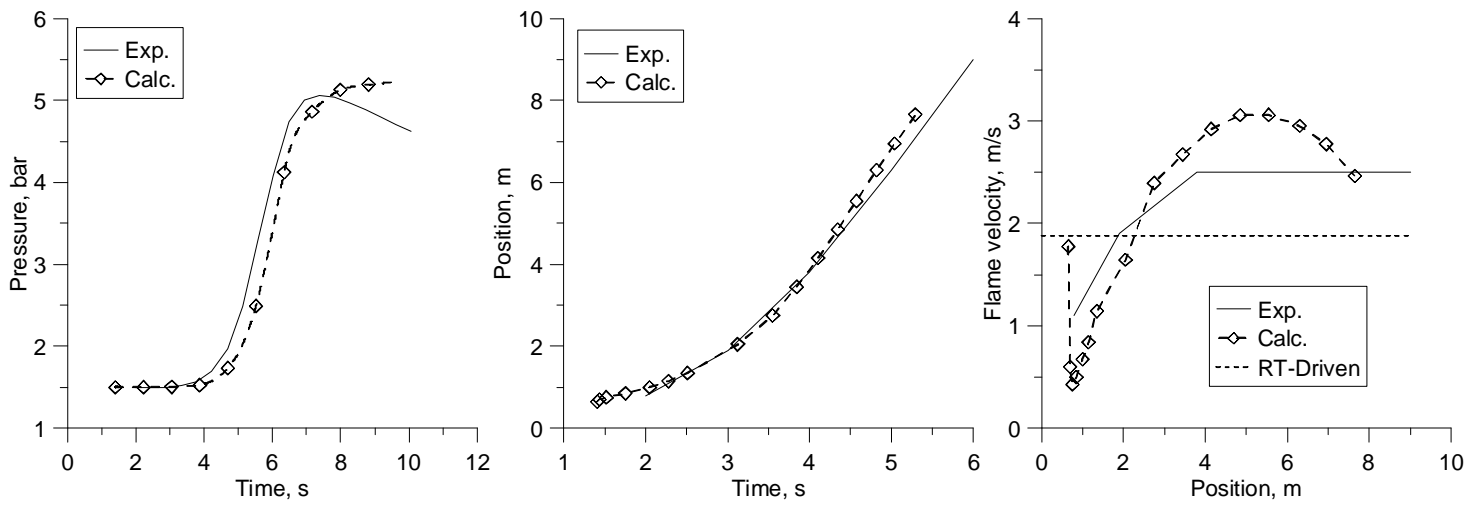

Figure 3: Left: pressure; center and right: flame position and velocity in the central axis in the THAI, HD-12 experiment. Legend: 'Exp.' means experimental, 'Calc.' calculation, 'RT' Rayleigh-Taylor. 

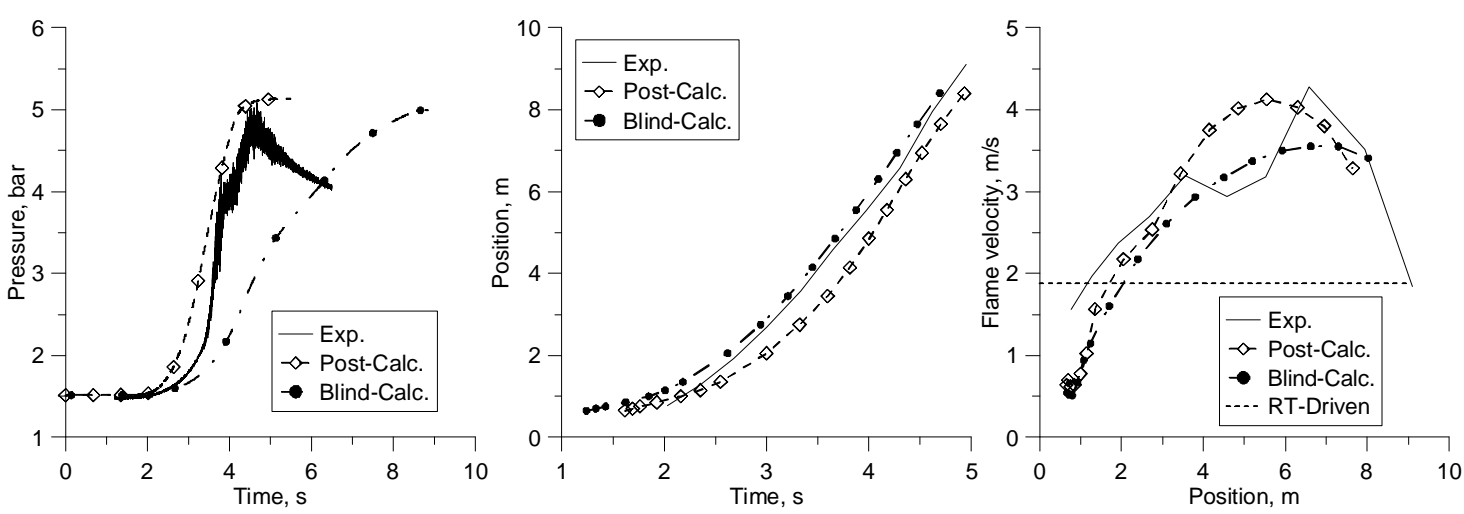

Figure 4: Left: pressure signals; center and right: Flame position and flame velocity in the central axis in the THAI, HD-22 experiment. Legend: 'Exp.' means experimental, 'Calc.' calculation, 'RT'

Rayleigh-Taylor.

In the experiments without steam no significant differences were found between the experimental pressure readings and the results of the calculations during the whole combustion process. The final divergence in pressure recordings is due to the fact that the convective heat losses were neglected in the calculation. A phenomenon that, following the results of the calculation becomes only important after the exhaustion of the fuel mixture (Figure 5). This is due to the fact that the flame does not touch the external walls (convective heat losses are proportional to temperature differences and speed of motion). In the HD-22 case (Figure 4 left) the good agreement between the experimental readings and the calculation results was achieved only in the 'post-calculation' phase. The 'blind' stage showed some deceiving results that are analyzed in the following section. Additionally, pre-calculation pressure results do not look, in principle, in agreement with the good positions and the velocities comparisons. In the figures located at the center, the flame position along the longitudinal axis of the vessel is represented both for calculations and experiments. The experimental flame positions were obtained processing the data available from the thermocouples. For all test cases an excellent agreement is shown both qualitatively and quantitatively. Since the calculation was performed without initial flow field perturbations, the results should not be able to capture the random nature of the flame evolution and therefore should stay between the both experimental lines. Both the acceleration of the flame and the steady-state propagation regime is reproduced with high accuracy. The results obtained for the experiment HD-22 (Figure 4 center) shows an excellent agreement between the experiment and simulations for both 'blind' calculations and the 'post-calculation' phase. The propagation of the flame in the vertical direction was good captured by both calculations, so that the pressure deviations obtained in the 'blind' phase could only be connected with the erroneous transversal flame propagation predictions.

The flame velocities found in the simulations are compared with the experimental data in the figures located on the right. The agreement for all cases is good. The irregular behavior of the flame, which can reach two transducers in the different positions at the same moment, cannot be reproduced in the calculation. The acceleration and the steady-state regimes were though well predicted. The deviations found in the flame propagation velocity of $0.5 \mathrm{~m} / \mathrm{s}$ should be considered as corresponding to the overall level of calculation accuracy. 


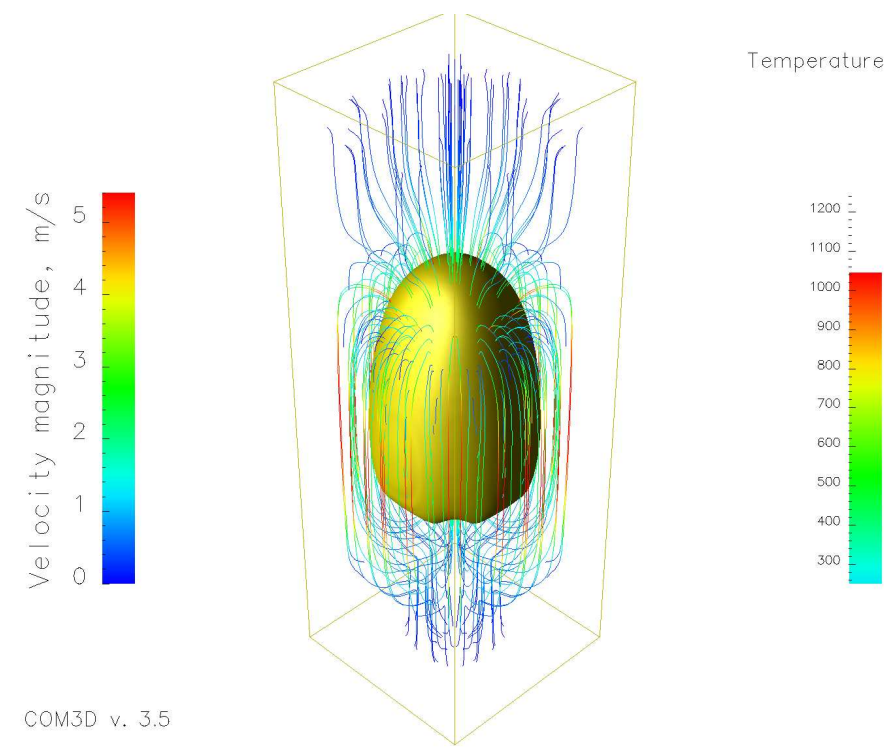

Figure 5: Temperature iso-surface for $800 \mathrm{~K}$ and stream-lines at $3.54 \mathrm{~s}$ after ignition for the HD-12 problem.
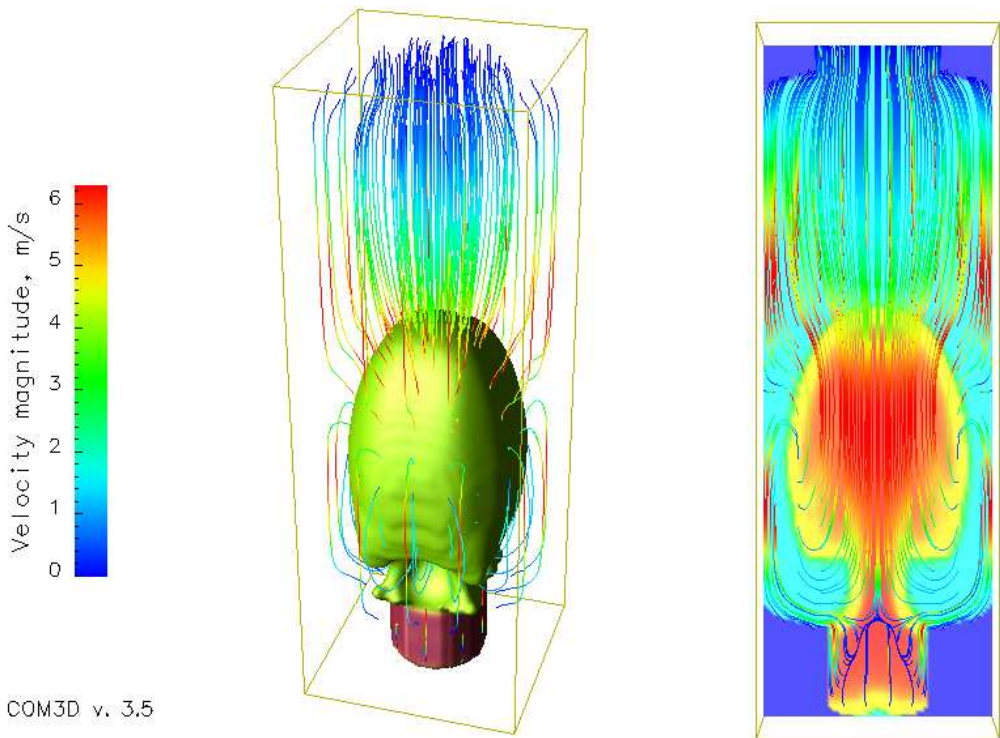

Temperature

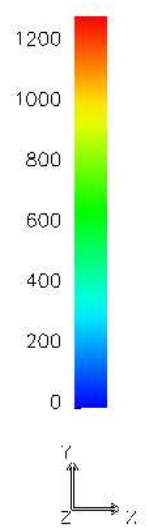

Figure 6: Temperature field and streamlines obtained for the HD-22 calculation at $2.2 \mathrm{~s}$ after the ignition.

\subsection{Rayleigh-Taylor (R-T) instability driven flame analysis}

Khokhlov et al. (1996) developed an algebraic flame velocity model, which was intended to describe buoyancy-driven turbulent pre-mixed flames. Its application is restricted to flames fulfilling the following conditions. First, the flame is assumed to be thin in comparison with the largest scale of turbulence. Second, the laminar burning velocity is much less than the turbulent velocity. Third, the turbulence is driven by the R-T instability in the gravitational field. The physical phenomenon development that results from those assumptions is as follows. After the ignition, the flame begins to propagate vertically. Because of the propagation against gravity the flame becomes turbulent due to the R-T instability. After a while the flame reaches a steady state propagation regime, when the propagation speed could be evaluated using the expression 
$\mathrm{S}_{t}=\frac{1}{2} \sqrt{g h \frac{\sigma-1}{\sigma+1}}$

where $\mathrm{g}$ stands for the acceleration of gravity and $\mathrm{h}^{2}$ represents the surface of the unperturbed flame. If the conditions stated before are fulfilled, the flame velocity does not depend on laminar flame speed.

For the mixtures in the HD-12, HD-15 and HD-22 tests, the Froude number $\mathrm{F}=\mathrm{S}_{\mathrm{L}}{ }^{2} / \mathrm{gh}$ was approximately equal to $1.2 \cdot 10^{-4}, 5.0 \cdot 10^{-4}$, and $5.2 \cdot 10^{-4}$, so that all of them are buoyancy driven processes. The turbulent flame velocity registered in the experiments and in the calculations is one order of magnitude larger than the laminar one. The fulfillment of the third condition, to be studied, determines the flame propagation regime.

The evaluation of the formula (9) for the mixtures used, as the result gives the values of $S_{t} \approx 1.88$, 1.86 , and $1.87 \mathrm{~m} / \mathrm{s}$ respectively. Those values are shown in the Figure 3 and Figure 4 at right. The prediction obtained for the case HD-12 (Figure 3 right) was remarkably good taking into account the crudeness of the assumptions made. Thus, with the certain degree of precaution, on the basis of such coincidence it can be concluded that the flame propagation regime in this experiment can be considered as at least partially driven by the R-T instability. The experimental results for test HD-12 show, as it is predicted by the theory of Khokhlov, a steady-state propagation regime. Unfortunately, the results of the simulation do not demonstrate the same behavior for this test. Although the flame velocity predicted is quantitatively very good some improvements in the modeling should be performed in the future in order to get better predictions for this kind of flames.

In the Figure 4 right the results of the test HD-22 are compared with the flame velocity predictions for R-T instability driven flame. For those experiments the higher difference between maximum experimental flame speed and theory predictions does not allow to identify the combustion process as being a buoyant driven. In this case, more probable, other mechanisms than the Rayleigh-Taylor instability are responsible for the turbulence generation. As an additional argument in favor of this statement serves the fact that the flame does not reach a steady-state regime, it accelerates until it reaches the top cover of the facility.

\subsection{Borghi diagram analysis}

With the view to get better insight into the processes taking place in the simulated experiments the observed flame propagation regimes can be analyzed with the help of the Borghi diagram (Borghi, 1988). For the systematic mixture examination, the Lewis, Markstein, Karlovitz and turbulent Reynolds numbers of all three conditions were calculated (see Table 4). Those magnitudes as well as the other data necessary to perform such analysis were selected in the same location, far away of the flame front and at a time when the flame has been reaching the middle of the facility. Only qualitative comparison between the cases is possible.

The gases composition of the problem HD-12 has a Lewis number approximately equal to 3.0 while the Markstein number is equal to -0.47 . Both values imply an unstable mixture prone to 'erratic' propagation and local quenching. The flame is located in the flamelet regime area in the border between the wrinkled and the wrinkled with pocket formation region $\mathrm{u}^{\prime} / \mathrm{S}_{\mathrm{L}} \approx 1.0$ For the HD-15 problem, the propagation regime still remains close to the line $\mathrm{u}^{\prime} / \mathrm{S}_{\mathrm{L}} \approx 1.0$. The main difference between the mixtures lies in the fact that the Ma $<0$ for $8 \%$ vol. $\mathrm{H}_{2}$ while $\mathrm{Ma}>0$ for $10 \% \mathrm{H}_{2}$ vol., which makes second composition much more stable. The mixture of the case HD-22 causes a different combustion regime. The integral scale of the turbulence, evaluated during the simulations, was significantly smaller, around one order of magnitude, that for the tests HD-12 and HD-15. The level of turbulence was also smaller. The combustion regime still lies in the flamelet region but in the laminar flamelet area; also, note, that this mixture has a Markstein number approximately equal to zero. Remarkably, that for all three mixtures the Markstein number, describing the sensitivity of the flame 
to its curvature, is completely different in each of the tests producing in our opinion three different flame propagation regimes.

Table 4: Characteristics of the gases

\begin{tabular}{ccccccc}
\hline Case & $\mathbf{R e}_{\mathbf{t}} \mathbf{}^{\mathbf{2}}$ & $\mathbf{K a}^{\mathbf{3}}$ & $\mathbf{D a}^{\mathbf{4}}$ & $\mathbf{L e}^{\mathbf{5}}$ & $\mathbf{M a}^{\mathbf{6}}$ & Combustion regime \\
\hline HD-12 & 852 & 0.02 & 1500 & 3.0 & -0.47 & Wrinkled flames \\
\hline HD-15 & 946 & $1.9210^{-3}$ & 1068 & 2.87 & 1.57 & Wrinkled flames \\
\hline HD-22 & 88 & 0.01 & 339 & 2.91 & 0.033 & Laminar flamelets \\
\hline
\end{tabular}

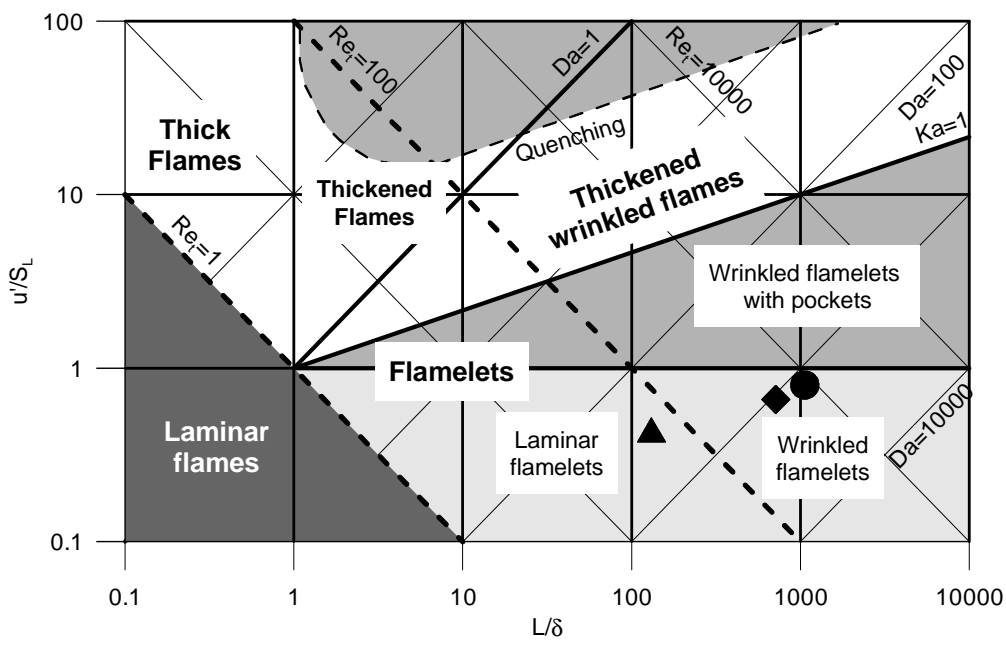

Figure 7: Borghi diagram. Circle denotes test HD-12, diamond HD15, triangle HD-22. Values for the turbulence obtained in the intermediate phase of the propagation. L, integral scale of the turbulence, $\delta$ flame thickness.

\subsection{Parametric instability analysis}

The pressure readings of the HD-22 experiments, which have strong oscillations appearing soon after the flame reaches approximately the half height of the facility, could not be explained as caused by wrinkling of the flame due to the Rayleigh-Taylor instability or just by the presence of a strong turbulent field. The spectrum obtained by the Fourier analysis of the pressure signal, shown in Figure 8 , shows a resonance in the first transversal harmonic ${ }^{7}$ (exact values are listed in Table 5).

The generation of pressure waves by flames propagating in closed volumes is a known problem. The interaction between them has been investigated decades since the early works of Markstein (1964).

${ }^{2}$ In the table $R e_{t}^{\prime}=\frac{L u^{\prime}}{v}$ in the diagram $R e_{t}=\frac{L u^{\prime}}{\chi}$ at first approach $R e^{\prime} \approx R e_{t}$

${ }^{3}$ Defined in (Poinsot T, 1991) as $K a=\frac{u^{\prime}}{S_{l}} \sqrt{\frac{v}{u^{\prime} L}}$

${ }^{4} D a=\frac{S_{L}^{2} L}{\chi u{ }^{\prime}}$

${ }^{5}$ Defined like in (Zeldovich, 1985) as $L e=D / \chi$

${ }^{6}$ Defined in (Zeldovich, 1985) as $M a=\frac{\chi-D}{\chi} \frac{E_{a}\left(T_{b}-T\right)}{2 R T_{b}^{2}}+\frac{D}{\chi}$

${ }^{7}$ To calculate the transversal characteristic frequencies, the speed of sound of the cold fuel was selected. 
The waves generated during such process can be described as weak shocks or sound waves. For weak shocks the typical time for the sound to traverse the burning chamber is much longer than the typical time of flame dynamics, here it is Darrieus-Landau (DL) instability typical time. In the opposite case such pressure perturbations can be considered as sound waves. For the problem we are dealing with, the DL typical growth rate frequency ${ }^{8}(120 \mathrm{~Hz})$ and the first transversal harmonic of the chamber (143 $\mathrm{Hz})$ are comparable. Thus, neither of the previous limiting cases is directly applicable.

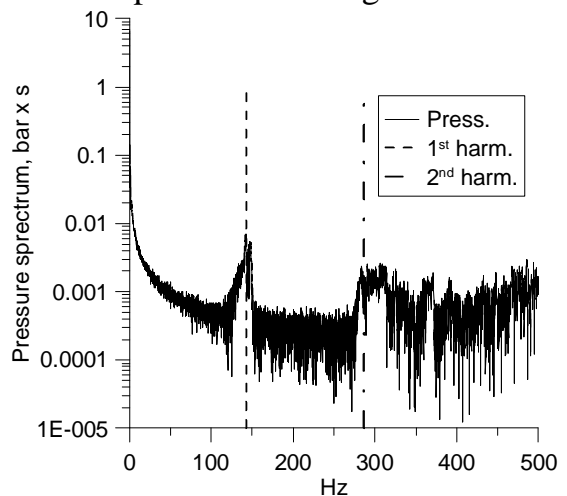

Figure 8: Spectrum of the pressure signal, first and second transversal harmonic.

Table 5: Sound speed and first transversal harmonic frequency for the three experiments analyzed.

\begin{tabular}{ccc}
\hline Case & Sound speed, $\mathbf{~ m} / \mathbf{s}$ & First harmonic frequency, $\mathbf{~ H z}$ \\
\hline HD-12 & 389.2 & 121.5 \\
\hline HD-15 & 440.5 & 137.5 \\
\hline HD-22 & 460.5 & 143.75 \\
\hline
\end{tabular}

Aware of this difficulty, the authors have decided to consider the waves as acoustic. The linear theoretical results contained in the reference (Bychkov, 2000) were applied to evaluate the enhancement of the combustion rate. If the previous modeling hypothesis is accepted, the flame is going to be subjected to the acoustic and the parametric instabilities. Following the references (Bychkov, 2000) and (Searby, 1986) the acoustic and parametric stability limits were calculated and ploted in Figure 9. Some detailled characteristics of the mixture utilized to perform the calculations were included in Table 6.

Table 6: Characteristics of the mixtures selected for the calculation of the stability and instability growth rate.

\begin{tabular}{|c|c|c|c|c|c|c|c|c|c|c|}
\hline $\begin{array}{l}\text { Marc. } \\
\text { Num. } \\
\text { Ma.9 }\end{array}$ & $\begin{array}{l}\text { Cin. } \\
\text { Visc. } \\
v \\
\mathrm{~m}^{2} / \mathrm{s}\end{array}$ & $\begin{array}{l}\text { Ther. } \\
\text { Diff. } \\
\text { X } \\
\text { m }^{2} / \mathbf{s}\end{array}$ & $\begin{array}{l}\text { Diff. } \\
\text { D } \\
\mathrm{m}^{2} / \mathrm{s}\end{array}$ & $\begin{array}{l}\text { Activ. } \\
\text { Energ. } \\
\mathbf{E}_{\mathrm{a}} / \mathbf{R}\end{array}$ & $\begin{array}{l}\text { Temp. } \\
\text { Producs } \\
\mathbf{T}_{\mathrm{b}} \mathrm{K}\end{array}$ & $\begin{array}{l}\text { Temp } \\
\text { fuel } \\
T_{0} K\end{array}$ & $\begin{array}{l}\text { Lam. } \\
\text { Flam. } \\
\text { Vel. } \\
\text { S }_{\mathrm{L}} \\
\mathbf{m} / \mathbf{s} \\
\end{array}$ & $\begin{array}{l}\text { Exp. } \\
\text { Ratio. } \\
\sigma\end{array}$ & $\begin{array}{l}\text { Acoust. } \\
\text { Frec. } \\
\text { Hz }\end{array}$ & $\begin{array}{l}\text { Red. } \\
\text { Accous. } \\
\text { Wave } \\
\text { Amp. } \\
\mathbf{U}_{\mathrm{a}} / \mathrm{S}_{\mathrm{L}} \\
\end{array}$ \\
\hline 3.18 & $\begin{array}{l}2.70 \\
10^{-5}\end{array}$ & $\begin{array}{l}3.4 \\
10^{-5}\end{array}$ & $\begin{array}{l}1.01 \\
10^{-4}\end{array}$ & 4810 & 1179 & 430 & 0.13 & 2.7 & 143 & 65. \\
\hline
\end{tabular}

The mechanism driving to the final registered unstable results was, in opinion of the authors, the following: In the first stage, the flame generated acoustic waves, which amplitude could be estimated (Bychkov, 2000) as $\mathrm{U}_{\mathrm{a}}=(\sigma-1) \mathrm{S}_{\mathrm{L}} \approx 0.5 \mathrm{~m} / \mathrm{s}$, triggered the acoustic instability. Then, in a feedback process, the amplitude of such oscillations (they could be calculated following the method stated in (Bychkov, 1999)) reached a level in which the stable band between the acoustic and the parametric area was overcome, very probable in the transversal direction (the amplitude of the stable band is proportional to the frequency of the acoustic oscillations, in the longitudinal direction the frequency

\footnotetext{
${ }^{8}$ Calculated following (Bychkov, 2000).

${ }^{9}$ Defined in (Searby, 1986) eq. (6).
} 
should be three times smaller). Then, another feed-back mechanism (parametric instability), was responsible for the transversal direction instability.
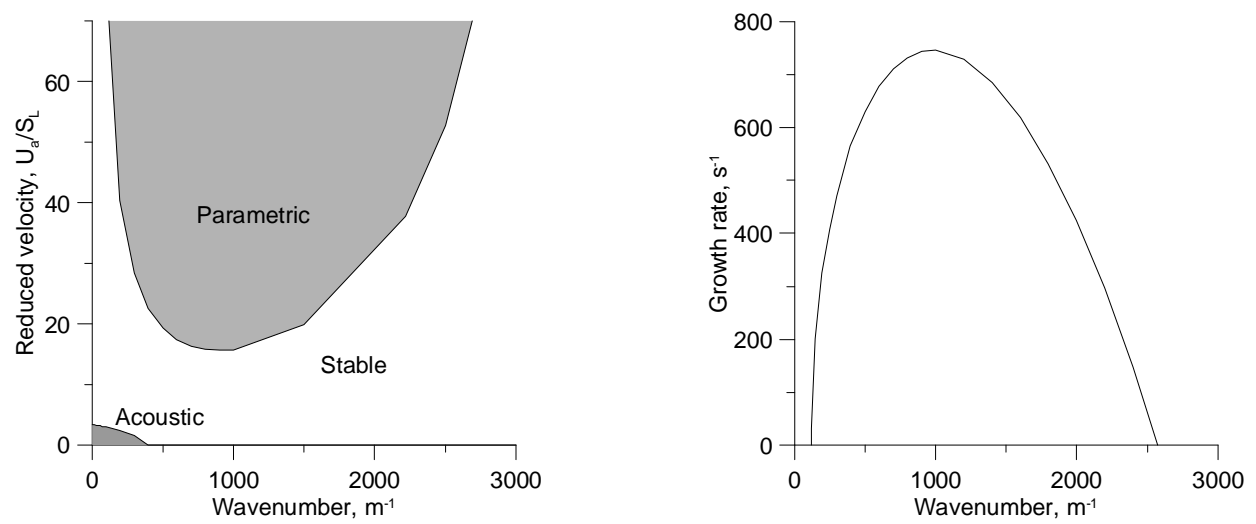

Figure 9: Left: Stability limits of the gases mixture for both the acoustic and the parametric instability.

Right: Growth rate of the parametric instability for the mixtures.

The equation (2) provides a way to calculate the enhancement of the mass consumption rate due to flame wrinkling strengthen by the instability. The sub-grid wrinkling generation and suppression factors, G and R (eqs. (3) and (4)) can be evaluated for this problem. The surface wrinkling factor $\Xi$ can be easily estimated to be approximately 1.79 in the equilibrium state $\mathrm{d} \Xi / \mathrm{dt}=0$.

The post-calculations for the HD-22 test were performed using the described enhancement mechanism. Good agreement between experimental results and simulation was obtained both for the pressure and for the flame position (see Figure 4).

In the opinion of the authors the reasons why the other mixtures do not suffer those parametric instabilities can be formulated as follows. A significant difference in the sound speeds between the mixtures in the experiments HD-12 and HD-22 exists (see Table 5). For the mixtures of the experiments HD-15 and HD-22 such difference is not as significant. Two competitive mechanisms appear: on one side HD-15 mixture has a much larger positive Markstein number (the width of the stability band between the parametric and the acoustic instability is proportional to it); on the other side, there exists a small reduction in the first harmonic frequency between the two cases. The band of stability of the problem HD-15 is finally wider and therefore the mixture does not suffer any flame surface enhancement due to parametric sight instability.

\section{CONCLUSIONS}

One 'blind' simulation and three post-test simulations for three large-scale experiments on hydrogenair combustion in lean mixtures were performed. The experiments included variation of the temperature: normal ambient and elevated; concentration of hydrogen and component content: hydrogen-air and hydrogen-air-steam. The results of the simulations were compared with the experiments and analyzed in details.

Although the conditions were highly similar and the hydrogen concentration was varied only from $8 \%$ to $10 \%$ vol. the distinctly different combustion regimes were identified. For the $8 \%$ vol. $\mathrm{H}_{2}$ mixture the analysis assumed a buoyant flame driven by the Rayleigh-Taylor instability. In case with a $10 \%$ vol. $\mathrm{H}_{2}$ dry mixture a buoyant flame driven by the low intensity turbulence field generated by its own motion was found. Finally, the mixture containing $10 \%$ vol. $\mathrm{H}_{2}$ diluted by $25 \%$ vol. of steam showed a combustion pattern mainly determined by the interaction of the flame with acoustic waves. Good agreement with the experimental data was obtained with the results of the simulations performed for each of the tests.

The observed phenomena, confirmed that the application of CFD combustion simulations in the area of nuclear safety requires an extremely cautious approach to obtain reliable and conservative results. 


\section{ACKNOWLEDGMENTS}

Sponsorship of the THAI experiments by the partners of the THAI OECD project (2007-2009) is gratefully acknowledged.

\section{REFERENCES}

Borgi, R., "Turbulent combustion modelling". Prog. Energy Combust. Sci. vol: 14 245-292. 1988.

Arntzen, Bjorn., "Modelling of turbulence and combustion for simulation of gas explosions in complex geometries. Thesis for Dr. Ing Degree." The Norwegian university for science and technology. 1998.

Bauwens, C. R. Chaffee, J., Dorofeev, S., "Vented explosion overpressures from combustion of hydrogen and hydrocarbon mixtures." International Journal of Hydrogen Energy. 2010 (in press).

Bychkov, V., "Analytical scalings for flame interaction with sound waves". Physics of Fluids - vol. 11 - number 10-. 1999.

Bychkov, V. V., Liberman, M.A., "Dynamics and stability of pre-mixed flames". Physics Reports 325, pp. 115-237. 2000.

Clement, B., Cantrel, L., Ducros, G., "State of the art report on iodine chemistry". Nuclear Energy

Agency. Committee on the safety of nuclear installations. JT03222514. NEA/CSNI/R (2007)1. 2007.

Efimenko, A.A., Dorofeev, S.B., "CREBCOM code system for description of gaseous combustion". Journal of Loss Prevention in the process industries. 2001, pp. 575-581.

Jimenez, J. "Turbulence and Vortex Dynamics". Notes for the Polytecnique course on turbulence. École Polytechnique, Paris, France, 2004 (personal communication).

Kanzleiter, T., Langer, G., "Quick Look Report Hydrogen Deflagration Tests HD-15, HD-16, HD-17, HD-18, HD-19, HD-20 and HD-24”. Reactor Safety Research Project 1501326 OECD-NEA THAI Project (contract 18 July 2007). 2007.

Kanzleiter, T., Langer, G., "Quick Look Report Hydrogen Deflagration Tests HD-1R, HD-4, HD-7, HD-8 and HD-10". Reactor Safety Research Project 1501326 OECD-NEA THAI Project (contract 18 July 2007). 2007.

Kanzleiter, T., Langer, G., "Quick Look Report Hydrogen Deflagration Tests HD-1R, HD-4, HD-7, HD-8 and HD-10". Reactor Safety Research Project 1501326 OECD-NEA THAI Project (contract 18 July 2007). 2007.

Khokhlov, A.M., Oran, E.S., Wheeler, J.C., "Scaling in bouyancy-Driven Turbulent Premixed Flames". Combustion and flame. vol. 105 pp. 28-34. 1996.

Yanez, J., Kotchourko, A., Lelyakin, A., "KYLCOM Model for the Calculation of Under-resolved Hydrogen Combustion Problems". Protocol of the Sixth ISFEH. Leeds, $11^{\text {st }}-16^{\text {th }}$ April, 2010 (in press). Launder, B. E., and Sharma, B. I., "Application of the energy dissipation model of turbulence to the calculation of flow near near a spinning disk". Lett. Heat Mass Trans . Vol. 1, No. 2, pp. 131-138. 1974.

Mahaffy, J., Chung, B., Dubois, F., et al, "Best practice guidelines for the use of CFD in nuclear reactor safety applications". Nuclear Energy Agency. Committee on the safety of nuclear installations. NEA/CSNI/R(2007)5. JT03227125. 2007.

Markstein, G.H., Nonstady flame propagation. Pergamon Press. 1964.

Poinsot, T., Veynante D., Candel, S., "Quenching processes and premixed turbulent combustion diagrams." Journal of Fluid Mechanics. 228:561-606. 1991.

Kotchourko, A., Breitung, W., Veser, A., "Reactive Flow Simulations in Complex 3D Geometries Using The COM3D Code”. 1999. 'Jahrestagung Kerntechnik' 99, Kerntechnische Gesellschaft e.V. Deutsches Atomforum e.V. Annual Meeting on Nuclear Technol.

Schmidt, H.P., Habisreuther, P., Leuckel, W., "A Model for Calculation Heat Release in Premixed Turbulent Flames.”. Comb Flame. 113:79. 1998.

Searby, G., Clavin, P., "Weakly turbulent, wrincled flames in pre-mixed gases". Comb. Sci. and Tech. vol. 46, pp. 167-193. 1986.

Zeldovich, Ya. B., Barenblatt, G.I., Librovich, V.B., Makhviladze, G.M., The mathematical theory of Combustion and Explosion. Consultants Bureau, New York \& London. 1985. 